\title{
Trabalho em Equipe: Representações Sociais de Profissionais do PSF
}

Teamwork: social representations of the family health program (FHP) professionals

Rosana Farias Batista Leite Faculdade de Ciências Médicas de Campina Grande-PB

Thelma Maria Grisi Veloso Universidade Estadual da Paraíba

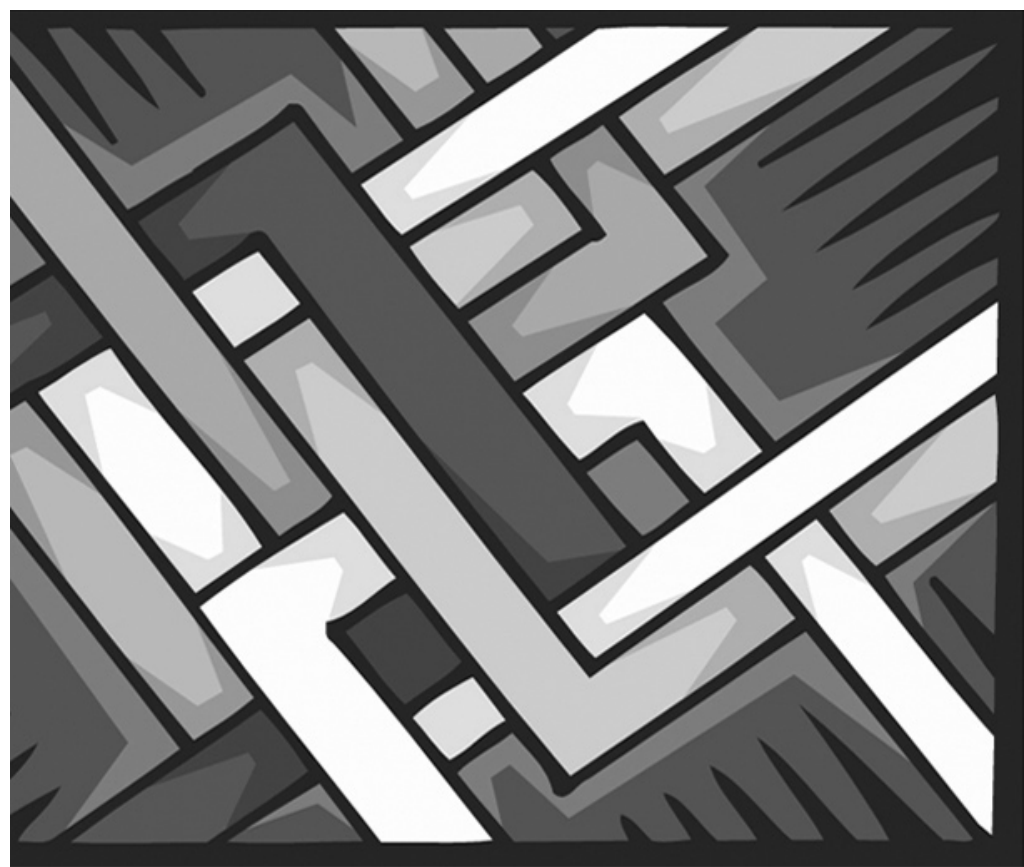


Resumo: Este artigo é fruto da análise das representações sociais de profissionais do Programa Saúde da Família (PSF) de Campina Grande-PB sobre o trabalho em equipe. Realizamos uma pesquisa qualitativa que foi desenvolvida à luz da teoria das representações sociais, tendo sido realizadas 24 entrevistas semi-estruturadas com profissionais de duas unidades de Saúde da Família - três médicos, três enfermeiros, quatro auxiliares de enfermagem, dois cirurgiõesdentistas, dois assistentes sociais, nove agentes comunitários de saúde (ACS's) e um auxiliar de consultório dentário. A análise das entrevistas foi feita a partir da proposta de análise de conteúdo temática. De modo geral, o trabalho em equipe no PSF é representado como uma convivência compartilhada no mesmo espaço físico, numa abordagem multiprofissional, sem que seja evidenciada a interdisciplinaridade. O desafio que se apresenta para os profissionais reside em romper o paradigma tradicional da saúde, calcado, entre outros aspectos, na fragmentação do conhecimento.

Palavras-chave: Representações sociais. Programa Saúde da Família (PSF). Trabalho em equipe. Interdisciplinaridade.

\begin{abstract}
This article is the result of the analysis of the social representations about teamwork done by professionals who work for the Family Health Program (PSF) in Campina Grande-PB. This was a qualitative research in the light of the theory of social representations. 24 semi-structured interviews were carried out with professional who work for two Health Family units: two doctors, three nurses, four assistant nurses, two dentists, two social assistants, nine community health agents (ACSs) and one dentistry attendant. The analysis of the interviews was carried out taking into account the approach of the analysis of thematic content. As a whole, the teamwork of PSF is represented as an experience shared by the people who work in the same premises, leading a multi-professional approach without any evidence of multidisciplinarity. These professionals face the challenge of breaking with the traditional health paradigm chiefly based on the fragmentation of knowledge.
\end{abstract}

Keywords: Social representations. Family Health Program (PSF). Teamwork. Interdisciplinary.

A partir do ano 1994, frente à necessidade de se efetivar a construção de um novo paradigma sanitário, o Ministério da Saúde (MS), por meio do Sistema Único de Saúde (SUS), implanta o Programa Saúde da Família (PSF), tendo como objetivo contribuir para a reorientação do modelo assistencial com vistas à promoção da saúde. O SUS impôs uma ruptura epistemológica com o velho modelo assistencial, o que contribuiu para a construção de um novo paradigma da produção social da saúde (Mendes, 1996).

No Município de Campina Grande-PB, o PSF foi instituído nesse mesmo ano, compondo, com mais treze municípios do país, as experiências pioneiras institucionalizadas pela Organização Mundial de Saúde (OMS). Enquanto projeto político, o PSF, nesse Município, apresentou avanços e retrocessos durante o seu processo de consolidação, avanços no sentido de que, desde o princípio, procura reafirmar e incorporar os princípios do SUS, priorizando as ações de promoção e prevenção em detrimento do assistencialismo curativo; quanto aos retrocessos, são resultado dos desentendimentos político-ideológicos entre os trabalhadores do Programa e o gestor municipal de saúde. 
...conjunto de conceitos, proposições e explicações, originado na vida cotidiana, no curso de comunicações interpessoais. Elas são equivalentes, em nossa sociedade, aos mitos e sistemas de crenças das sociedades tradicionais, podem também ser vistas como a versão

contemporânea do senso comum. (Moscovici, 1981, citado por Sá, 1996, p. 31)
Entendemos que o avanço dessa proposta está condicionado a vários fatores, isto é, o PSF será aquele em que, em cada situação concreta, os sujeitos sociais submetidos a determinadas relações econômicas, políticas e ideológicas conseguirem imprimir a marca de seu projeto. Nesse sentido, dentre os inúmeros determinantes da direção tomada pelo programa, evidenciamos a formação dos profissionais que participam desse processo.

A opção do MS de não centralizar o PSF em um único profissional de saúde - o médico - visa a enfatizar a idéia de equipe interdisciplinar, com o objetivo de cumprir o princípio da integralidade na saúde, concebendo cada indivíduo como uma totalidade, tanto na promoção como na prevenção, cura e reabilitação da saúde; valoriza, dessa forma, a "soma de olhares" de diferentes profissionais.

Acreditamos que as representações sociais (RS) de profissionais que compõem as equipes são reveladoras de possíveis limites e/ou perspectivas de avanços dessa prática. Nesse sentido, realizamos uma pesquisa para elaboração da dissertação de mestrado em Saúde Coletiva que teve como objetivo principal analisar as RS de profissionais sobre o trabalho em equipe no PSF de Campina Grande-PB. Os objetivos específicos foram analisar os limites e perspectivas do trabalho em equipe no PSF e verificar se há intercâmbio de saberes voltado para a construção de um trabalho interdisciplinar ou se prevalece o trabalho cotidiano fragmentado.

Fundamentamo-nos, na área da Psicologia social, na teoria das representações sociais (TRS) segundo as contribuições de Serge Moscovici. Entendemos as RS como um ...conjunto de conceitos, proposições e explicações, originado na vida cotidiana, no curso de comunicações interpessoais. Elas são equivalentes, em nossa sociedade, aos mitos e sistemas de crenças das sociedades tradicionais, podem também ser vistas como a versão contemporânea do senso comum. (Moscovici, 1981, citado por Sá, 1996, p. 31)

Optamos por uma pesquisa qualitativa, sendo utilizados como principais instrumentos de coleta de dados a entrevista semi-estruturada e a observação participante com registro em diário de campo. As equipes escolhidas foram: Monte Castelo I e II e Tambor I e II.

Inicialmente, fizemos o reconhecimento do campo de estudo, situação na qual pudemos observar a rotina de trabalho das unidades básicas de saúde escolhidas. A partir daí, selecionamos, dentre as atividades desenvolvidas cotidianamente pelos profissionais, aquelas que seriam alvo de nossa observação, quais sejam: realização de visitas domiciliares com a participação dos profissionais e reuniões mensais dos grupos de hipertensos, diabéticos, saúde mental e planejamento familiar. Os dados provenientes da observação participante foram registrados em um diário de campo, que serviu de suporte para a análise das representações dos profissionais.

Foram entrevistados 24 profissionais das referidas unidades: sete no Monte Castelo I, seis no Monte Castelo II, cinco no Tambor I e seis no Tambor II. A faixa etária variou entre 25 (vinte e cinco) e 47 (quarenta e sete) anos, sendo 22 (vinte e dois) deles do sexo feminino e apenas 02 (dois) do sexo masculino. Quanto ao grau de instrução, 11 (onze) cursaram pós-graduação, 13 (treze) possuem curso superior completo, 10 (dez), o ensino médio, 12 (doze) concluíram o curso profissionalizante de auxiliar de enfermagem, 
03 (três) possuem o curso pedagógico e somente 01 (um) possui apenas o curso fundamental. É importante destacarmos que 02 (dois) auxiliares de enfermagem e 01 (um) agente comunitário de saúde possuem nível superior: fisioterapia, serviço social e Sociologia, respectivamente.

O número de entrevistas foi delimitado pelo critério de acessibilidade e pelo critério do ponto de saturação (Sá, 1998). As entrevistas foram submetidas à análise de conteúdo temática (Bardin, 1977).

Neste artigo, refletiremos sobre as RS desses profissionais sobre o trabalho em equipe. Assim, em primeiro lugar, situaremos rapidamente o leitor sobre os princípios que norteiam o trabalho em equipe nas atuais propostas de política de saúde e sobre o conceito de interdisciplinaridade. Em seguida, deter-nos-emos na análise e discussão das RS dos entrevistados sobre o trabalho em equipe no PSF.

\section{O trabalho em equipe e a interdisciplinaridade na saúde: desafios para os profissionais do PSF}

O trabalho em equipe é essencial no processo de inversão de modelos de atenção à saúde, em que a horizontalidade nas relações começa a constituir o cotidiano do trabalho. Como conceito, o trabalho em equipe pode ser desdobrável, em partes, definidas por Souza e Mourão (2002) como:

Trabalho: atividade contínua e necessária a uma ação que envolve o conjunto de arranjos institucionais que transformam as relações sociais de produção nos locais de trabalho (relação de subordinação e dominação e/ou de cooperação e conflito).
Equipe: conjunto de profissionais que se aplicam a desenvolver trabalho conjunto a partir da definição de objetivos. (p. 35, grifos dos autores)

O trabalho em equipe na saúde representa um processo de relações a serem pensadas pelos próprios trabalhadores e possui múltiplas possibilidades de significados.

Peduzzi (2001) ressalta que esse trabalho não pressupõe abolir suas especificidades, pois as diferenças técnicas possibilitam a contribuição da divisão do trabalho para a melhoria dos serviços prestados, à medida que a especialidade permite não só o aprimoramento do conhecimento e do desempenho técnico em determinada área de atuação bem como maior produção.

O trabalho em equipe tem ocupado uma posição de destaque na proposta do PSF como um importante recurso de trabalho, na medida em que leva a um rompimento da dinâmica dos serviços centrados na figura do médico, configurando-se a possibilidade de uma abordagem mais integral e resolutiva.

Apesar de recomendar que o PSF utilize uma equipe mínima (médico, enfermeiro, auxiliar de enfermagem, cirurgião-dentista, auxiliar de consultório odontológico e agente comunitário de saúde), o Ministério da Saúde admite a incorporação de outros profissionais da área da saúde em conformidade com as demandas e características de organização dos serviços locais. A equipe insere-se em um determinado grupo populacional que é composto por 600 a 1000 famílias, concretizando, assim, a idéia de vínculo que tem como princípio a construção de referências do usuário com os profissionais que deverão se responsabilizar pelo cuidado da sua saúde (Ministério da Saúde, 2001). 
Farias (2005) ressalta que o PSF "traz em seu bojo a necessidade de desconstruir e reconstruir práticas historicamente produzidas. A ruptura do modelo hegemônico de atenção à saúde pressupõe a transformação do modelo de formação dos profissionais dessa área" (p. 34). No entanto, segundo a autora, as instituições formadoras continuam encaminhando, a cada ano, profissionais formados numa lógica tecnicista, fragmentada.

O trabalho em equipe na área da saúde apresenta-se de modo complexo no interior de uma prática que, historicamente, é constituída com base na concentração de poderes e na fragmentação do conhecimento. A interdisciplinaridade no trabalho em equipe no PSF se apresenta como uma alternativa para provocar mudanças na formação dos profissionais envolvidos no programa e também para favorecer a efetivação de um espaço democrático na relação de trabalho. Entretanto, os profissionais da área da saúde não podem ser vistos como os únicos responsáveis pela desconstrução/construção de uma prática interdisciplinar. É necessário que se levem em conta as condições objetivas, históricas, materiais e subjetivas para a sua concretização.

O conceito de interdisciplinaridade é complexo e comporta várias interpretações. De acordo com Demo (1997), a interdisciplinaridade pode ser definida como "...a arte do aprofundamento com sentido de abrangência, para dar conta, ao mesmo tempo, da particularidade e da complexidade do real" (p. 88). O autor ainda afirma que a interdisciplinaridade surge como paradigma questionador do modelo positivista, que fragmentou o saber e dicotomizou o conhecimento. Verifica-se, assim, que o termo interdisciplinaridade nos remete à idéia de colaboração entre diversas áreas de saber e de conhecimento em projetos que envolvem tanto as diferentes disciplinas acadêmicas quanto as práticas não-científicas e que incluem atores e instituições diversas.

Souza (1999) observa que o sentido desse conceito vem sendo desvirtuado ou por desconhecimento ou por apropriação restrita do mesmo, o que contribuiu para fazer perdurar a justaposição de disciplinas sem integração conceitual entre elas, em que cada uma reproduz apenas sua especificidade, com total ausência de comunicação.

Ressaltamos a importância de se estabelecer uma diferença entre interdisciplinaridade e outros conhecimentos semelhantes, como multidisciplinaridade e pluridisciplinaridade. Em relação à multidisciplinaridade, Japiassu (1976), afirma ser essa uma “...simples justaposição, num trabalho determinado, dos recursos de várias disciplinas, sem implicar necessariamente um trabalho de equipe e coordenado" (pp. 73-76). A pluridisciplinaridade, por sua vez, é definida pelo autor como uma justaposição de diversas disciplinas situadas no mesmo nível hierárquico e agrupadas de modo a fazer aparecer as relações existentes entre elas - um sistema de um só nível e de objetivos múltiplos, com cooperação, mas sem coordenação (Japiassu, 1976). A respeito da interdisciplinaridade, acrescenta que esta se caracteriza pela

...intensidade das trocas entre os especialistas
e pelo grau de integração real das disciplinas,
no interior de um projeto específico de
pesquisa... O interdisciplinar vai além do
simples monólogo de especialistas ou do
diálogo paralelo e tem como horizonte o
campo unitário do conhecimento. (Japiassu,
1976, p. 73, grifos nossos) Conceituado dessa forma, o termo interdisciplinaridade sugere um trabalho 
integrado e compartilhado com as diversas áreas do saber, remetendo-nos ao conceito de trabalho em equipe veiculado pelo PSF.

Nesse sentido, Gomes e Deslandes (1994, citado por Costa, 2002) afirmam que "...a interdisciplinaridade no campo da saúde pública passa a ter status de necessidade interna diante de problemas complexos que a saúde impõe" (p. 40). Os autores apontam, ainda, quatro obstáculos enfrentados pela interdisciplinaridade nesse campo: a tradição positivista e biocêntrica, os espaços de poder cristalizados pela rigidez disciplinar, a falta de comunicação entre as instituições de ensino e pesquisa e as dificuldades inerentes à interdisciplinaridade (operacionalização de conceitos, métodos e práticas entre as disciplinas).

Teixeira e Nunes (2004), no artigo "A Interdisciplinaridade no PSF: uma Utopia", nos convidam a refletir sobre a interdisciplinaridade no SUS e, particularmente, no PSF. As autoras indagam:

Como mudar as relações de trabalho com um modelo de atenção que privilegia o biológico, a doença, a especialização, em que o maior avanço se limita a uma prática multiprofissional - a médica - fragmentada e que tende a desqualificar os outros saberes? Como, então, horizontalizar as relações de poder se estas estão imbricadas com o saber? A interdisciplinaridade, ao significar reciprocidade e mutualidade, exige relações sociais horizontais, diferente do posto no modelo assistencial de saúde tradicional, hegemônico. Significa ouvir/ pensar o que o outro diz/pensa e conhece, e mais do que isso, implica trabalhar com o pensar do outro, introjetar novos/ outros conhecimentos, para a partir daí criar novas práticas, isto é, atuar de forma "nova", criativa. Por isso, indica uma atitude "diferente", pois exige trabalhar com uma visão de mundo, de totalidade. (Teixeira \& Nunes, 2004, p. 125, grifos dos autores)
Salientamos que o próprio MS reconhece que a formação acadêmica dos profissionais que compõem a equipe mínima do PSF não atende ao desafio de mudança do paradigma de atenção à saúde vigente (Ministério da Saúde, 2003). Reconhecendo a existência dessa lacuna nos cursos de graduação e objetivando capacitar e habilitar os profissionais de saúde que atuam no PSF, o MS, por meio do Departamento de Gestão de Educação na Saúde, criou, em todo o território nacional, os Pólos de Capacitação, Formação e Educação Permanente e de Pessoal em Saúde.

O modelo multiprofissional tradicional constitui um grande desafio a ser superado, pois focaliza o indivíduo e sua compartimentalização. As várias categorias profissionais trabalham paralelamente, de forma isolada, havendo pouca ou até mesmo nenhuma discussão entre as mesmas, o que gera uma atenção fragmentada. O enfrentamento da complexidade dos problemas de saúde da população requer que as várias categorias profissionais trabalhem em conjunto, a partir da integração dos campos de conhecimento acumulados nas diversas profissões e também do saber da comunidade, este reconhecido como importante fonte de conhecimento.

Parreiras e Martins Júnior (2004) revelam que o que caracteriza a ação interdisciplinar é a busca e o desejo de promover o diálogo com os outros saberes em tantas circunstâncias quanto os temas trabalhados permitirem. Dessa forma, a ação interdisciplinar se materializa numa busca coletiva por caminhos comuns aos saberes envolvidos, tomando como ponto de partida o seu campo de especialização.

O questionamento/reflexão do trabalho em equipe por meio do "olhar interdisciplinar" 
O trabalho em equipe é como se fosse trabalhar em família, resgatando

o pleno sentido de família, é um trabalho harmonioso, é um trabalho de amizade aonde existe verdade, onde existe sinceridade. (A.E.I $-H, A)$ parece-nos um caminho fértil para que a atenção básica se fortaleça e alavanque as mudanças almejadas. No tenso quadro de implementação da política de saúde, particularmente no Município em que esta pesquisa se desenvolveu, é relevante o reconhecimento das RS dos profissionais sobre o trabalho em equipe no PSF, pois os mesmos desempenham papel fundamental nas ações de saúde por estarem diretamente vinculados à prestação de serviços, às estruturas de produção dos mesmos e à necessidade de articular respostas para a organização e a demanda social.

Nesse sentido, a seguir, serão objeto de análise e discussão as RS elaboradas pelos profissionais entrevistados acerca do trabalho em equipe e do trabalho interdisciplinar.

\section{As representações sociais do trabalho em equipe no PSF}

No que se refere ao trabalho em equipe, constatamos que as RS dos profissionais, em sua grande maioria, evidenciam um componente valorativo. Para alguns, o trabalho em equipe é "estar em família", para outros, é "respeitar o colega", e ainda há aqueles que representam o trabalho em equipe como "complemento". Com relação ao trabalho interdisciplinar, verificamos que os entrevistados o representaram de diferentes formas, tais como "trabalhar com várias profissões", "troca de diálogo de saberes", "construção", "integralidade" e "desconhecimento do que seja trabalho interdiciplinar".

Trabalhar em equipe é "como estar em família"

Durante as entrevistas realizadas, aparece de forma enfática, na fala de alguns profissionais de nível médio (ACS, ACD e auxiliar de enfermagem), a representação do trabalho em equipe como "estar em família", associado a sentimentos de "harmonia", "amizade" e "sinceridade". Assim se expressa um dos entrevistados:

O trabalho em equipe é como se fosse trabalhar em família, resgatando o pleno sentido de família, é um trabalho harmonioso, é um trabalho de amizade aonde existe verdade, onde existe sinceridade. (A.E.I $\mathrm{H}, \mathrm{A})$

O discurso transcrito acima evidencia uma idealização da harmonia existente não só entre os membros de uma equipe de trabalho como também entre os membros da própria entidade familiar. Ele sinaliza uma representação romântica e utópica da família quando desconsidera, em sua fala, as heterogeneidades, os conflitos existentes nos dois contextos: família e trabalho.

Recorrendo à TRS, nós nos deparamos com o processo de formação das representações, isto é, a objetivação e a ancoragem, que estão intrinsecamente interrelacionadas. O processo de objetivação é entendido por Moscovici (2004) como o processo de tornar concreto o que é abstrato. Destaca o autor: “...objetivar é descobrir a qualidade icônica de uma idéia, ou ser impreciso, é produzir um conceito de uma imagem" (Moscovici, 2004, pp. 71-72). Já o processo de ancoragem consiste em incorporar o estranho e o novo ao sistema de pensamento pré-existente (Moscovici, 2004). Em outras palavras, ancorar é encaixar o não familiar via processo de classificação.

Assim, supomos que os profissionais recorreram à concepção que tinham de família (conhecimento pré-existente) para construir a representação do trabalho em equipe (conhecimento novo, estranho), ou seja, a construção desse novo conhecimento 
foi ancorado pelos profissionais na posição/ classificação de família.

No trabalho em equipe todos são iguais

Nas representações sobre o trabalho em equipe, foi ressaltada também a questão da igualdade. Vejamos as falas a seguir:

No trabalho em equipe, a gente tudo se combina, a gente não tem assim diferença, considera todas as pessoas iguais, porque tanto faz a assistente social como a médica, o vigia, tudo são igual pra gente, não tem diferença, é tudo igual. (ACS II - M, D) Por que eu me sinto bem dentro do PSF? Justamente por isso. Não sei mais do que os outros, nem os outros sabem mais que eu. (AE II - M, C)

As representações de trabalho em equipe como igualdade entre os membros são exacerbadas quando desconsideram as diferenças existentes. $\mathrm{O}$ "valer mais do que o outro" confunde-se com o "saber mais do que o outro", que, a nosso ver, no último caso, não representa nenhuma subalternidade na relação, sendo inclusive um componente importante no trabalho interdisciplinar, que pressupõe as especificidades do conhecimento profissional. Como adverte Demo (1997), “...a riqueza do grupo advém de duas coisas essenciais: da competência especializada de cada um e da capacidade de aprendermos juntos" (p. 120).

Trabalhar em equipe é respeitar o espaço e a opinião do colega

Diante da pergunta "O que você entende por trabalho em equipe?", os profissionais construíram representações associadas a respeito da questão. Vejamos o discurso abaixo:
Trabalhar em equipe é você trabalhar respeitando as opiniões dos outros... é você, em primeiro lugar, respeitar o outro, é você ver o outro que está do seu lado e trabalhar em conjunto, respeitando, dando sua opinião, dando suas sugestões, e o consenso, a equipe que decide o que é melhor. (A. SOCIAL II - M, C/D)

O discurso acima sinaliza o processo de decisão democrática no trabalho em equipe, caracterizado pela consideração e respeito pelas opiniões dos membros do grupo, conforme destaca a assistente social, ao falar que "trabalhar em equipe é você trabalhar respeitando as opiniões dos outros".

Verificamos, no entanto, que outro entrevistado se pronuncia diferentemente, denunciando, em alguns momentos, a falta de "respeito":

No trabalho em equipe, às vezes tem pessoas que não entende seu trabalho, que não aceita seu modo de trabalho, que não pensa como você..., que não respeita as suas decisões... (ACD I - M, A/B)

Desse modo, identificamos representações que expressaram a existência de momentos de conflitos entre as equipes; além disso, o cotidiano desses profissionais, observado durante o trabalho de campo, deixava transparecer diferenças marcadas pelas relações de poder, saberes e decisões.

Alguns profissionais entrevistados não se sentem pertencentes à equipe. Observamos que a idéia de homogeneidade e de igualdade não está presente nas representações de todos os agentes comunitários. No discurso a seguir, por exemplo, o ACS demonstra não se sentir membro da equipe, da "família profissional" em determinadas situações. Vejamos como se expressa: 
Eu acho que os agentes de saúde é uma parte, e a equipe daqui é outra. A equipe pra mim do PSF é um médico, uma enfermeira e um auxiliar. ...Eu acho que a gente faz parte dos agentes de saúde. (ACS $I-M \cdot B)$
Em palavras, ACS é a estrutura de tudo (pausa), ACS é a raiz, é alicerce, é a base, mas às vezes, na prática, é o pequenininho. ACS é equipe só na hora das obrigações, atribuições, na hora de se reunir. Equipe é aquela hierarquia: médico, enfermeiro, auxiliar, assistente social. ACS deixou de ser equipe. Sabe aquelas reuniões (na Secretaria de Saúde), são fechadas, ACS não participa..., nos tratam e respeitam muito bem, agora, em determinadas situações é que faz com que o ACS se sinta por fora da equipe. (ACS I-M, A)

Outro ACS é mais enfático ao afirmar que, de fato, os agentes comunitários não fazem parte da equipe:

Eu acho que os agentes de saúde é uma parte, e a equipe daqui é outra. A equipe pra mim do PSF é um médico, uma enfermeira e um auxiliar. ...Eu acho que a gente faz parte dos agentes de saúde. (ACS I - M.B)

As falas dos ACSs revelam, de um modo geral, ressentimentos, preconceitos e conflitos. A manifestação desses sentimentos também foi constatada por Péret (2001, p. 162) em pesquisa realizada também no PSF de Campina Grande. Segundo a autora, os agentes comunitários "parecem viver, dentro do lugar ocupado na hierarquia institucional, um duplo sentimento de cordialidade versus antagonismo. Buscam convencerse da existência de relações familiares e fraternas no interior da Unidade de Saúde da Família".

\section{Trabalho em equipe é complemento}

Conforme mostra o discurso abaixo, ainda quando perguntamos sobre o trabalho em equipe, há quem o represente como complemento, associado à contribuição:

Trabalho em equipe é você trabalhar não de uma forma isolada, você trabalhar com o outro, assim, cada um dando sua contribuição, lógico, cada um respeitando a especialidade do outro, mas um complementando a ação do outro e nunca fazendo aquela coisa isolada... (A. SOCIAL I - M, A/B)

Observamos, nesse discurso, um reconhecimento e uma valorização do saber do outro profissional que sugere uma relação horizontal dentro da equipe, ainda que o entrevistado não se refira ao trabalho em equipe e às suas variantes (multidisciplinar, pluridisciplinar, interdisciplinar).

O trabalho em equipe, como complementação, aparece também associado à ajuda, como na fala abaixo:

Trabalho em equipe é isso, de um profissional ajudar o outro, a gente não tá só naquele problema, a responsabilidade não fica só numa pessoa..., um ajuda o outro. (ACS I - M, A)

Esse discurso ressalta a importância da ajuda no que diz respeito à divisão de tarefas, na medida em que sempre se pode contar com a ajuda do outro profissional na resolução de problemas. Nogueira (2000) aponta a inter-relação pessoal no trabalho em saúde como necessária, chegando a colocá-la como decisiva para a eficácia das práticas. Nas entrevistas e na observação de campo, percebemos ainda que a cooperação entre os profissionais é praticada e valorizada, o que influencia favoravelmente o estabelecimento de relações.

Nesse sentido, há quem enfatize a dimensão das relações pessoais baseadas no sentimento de amizade/cumplicidade e camaradagem no trabalho em equipe:

É cada um fazer a sua parte, assim cada um tem que fazer o seu trabalho, mas nunca deixar de quando o outro precisar, poder ajudar, né? Minha equipe é a primeira, mas sempre que eu chego e uma precisa de mim, 
Um trabalho interdisciplinar é um trabalho que tem vários profissionais, de várias áreas, médico, enfermeiro,

dentista, assistente social, psicólogo, que trabalham assim em conjunto, para um determinado fim, e todos têm o mesmo objetivo. (MED II - M, C) eu ajudo. Eu acho que equipe é isso, é um precisar do outro, o outro tá ali, na falta de um, o outro ajudar, o outro cobrir, que acontece de um adoecer, um faltar, e aí o outro tá ali pra dar uma força, eu acho que é isso... (ACS II - M, C)

Entretanto, vale destacar que supomos, a partir dos relatos dos entrevistados, que a ajuda se transforma numa simples atividade de substituição de profissionais, não havendo espaço para trocas substantivas. Tal constatação sugere que, para os profissionais entrevistados, o ato de ajudar não significa fazer com o outro, mas sim, fazer para o outro, como também tivemos oportunidade de observar, durante o trabalho de campo, que um profissional substituía (ajudava) um outro na condição de, em um outro momento, ser "ajudado".

Vale ressaltar que verificamos, nas RS ora em estudo, a prevalência de uma compreensão restrita do que seja trabalho em equipe, sendo este praticamente equiparado ao trabalho multiprofissional. No intuito de verificar se as representações dos entrevistados sobre o trabalho no PSF apontavam o componente interdisciplinar na perspectiva de atender os pressupostos do SUS com vistas à construção de um novo modelo assistencial de saúde já explicitado, indagamos aos profissionais o que entendiam sobre o trabalho/ações interdisciplinares. Identificamos, a partir daí, algumas representações significativas das quais nos ocuparemos a seguir.

Trabalho interdisciplinar "é trabalhar com várias profissões"

Alguns entrevistados, ao abordarem o tema, responderam que consideravam o trabalho interdisciplinar um trabalho com um conjunto de profissões. Atentemos para a representação a seguir:
Um trabalho interdisciplinar é um trabalho que tem vários profissionais, de várias áreas, médico, enfermeiro, dentista, assistente social, psicólogo, que trabalham assim em conjunto, para um determinado fim, e todos têm o mesmo objetivo. (MED II - M, C)

Na fala acima, verifica-se, se considerarmos as contribuições teóricas de Demo (1997) e Japiassu (1976) adotadas em nossa pesquisa, um pequeno avanço na concepção do trabalho em equipe, tendo em vista que, para o entrevistado, a equipe é um espaço no qual todos devem ter o mesmo objetivo.

Com base no pensamento dos referidos autores, é possível constatar, no entanto, que essa representação parte de um conceito limitado do que seja interdisciplinaridade, na medida em que o trabalho interdisciplinar é visto apenas como um conjunto de profissionais que trabalham com os mesmos objetivos, não especificando exatamente como o mesmo deveria se processar e quais seriam os seus principais elementos. Demo (1997) nos chama a atenção para o fato de que

\begin{abstract}
Não é qualquer grupo que pode ser tomado como interdisciplinar. Para sê-lo, é condição prévia que seja composto de especialistas diferentes, sobretudo muito diferentes, ou de campos opostos. Assim, não é o número maior de pessoas no grupo que traz a interdisciplinaridade, mas sua formação diversificada (p. 111, grifo do autor)
\end{abstract}

Japiassu (1976) acrescenta que a presença de profissionais de várias áreas não é suficiente para o desenvolvimento do trabalho interdisciplinar, sendo imprescindível a existência de um diálogo compreensível entre as disciplinas/profissões. De acordo com o autor, a simples troca entre organizações disciplinares não configura um trabalho interdisciplinar. 
O trabalho interdisciplinar entendido como troca/diálogo de saberes

Tendo como parâmetro nosso referencial teórico, percebemos, nas representações dos entrevistados, um avanço sobre a concepção de trabalho interdisciplinar, na medida em que expressam o componente de troca de saberes e aquisição de novos conhecimentos:

Trabalho interdisciplinar (pausa), o nome já é bem claro, interdisciplinar, então, entre as disciplinas. Troca de saberes... interdisciplinar, no meu ponto de vista, ele tem muito a ver com interprofissionais. (ENF I - M, A)

Um dos entrevistados, no entanto, associa trabalho interdisciplinar ao trabalho multiprofissional, quando expressa:

É quase um trabalho multiprofissional... num mesmo ambiente, vários conceitos, várias visões. (MED I - M, B)

O entrevistado acima, ao estabelecer uma comparação entre os dois tipos de trabalho, toma o multiprofissional como referência ideal, demonstrando desconhecer a discussão conceitual já referida por nós entre os elementos que o diferenciam do trabalho interdisciplinar. Com base no discurso acima, é bom lembrar que Peduzzi (1998) salienta que o trabalho em equipe multiprofissional não equivale à interdisciplinaridade, mas é uma prática que expressa a possibilidade de integração das disciplinas científicas.

Retomando as entrevistas, observamos que as falas de alguns profissionais sinalizam outros avanços na compreensão do que seja trabalho interdisciplinar:

Um trabalho interdisciplinar eu entendo que seja essa comunicação, diálogo entre os profissionais no dia a dia, isso é uma rotina..., é a gente procurar outro profissional para discutir um problema, trocar experiências, é procurar soluções dentro daquele problema que você não pode na sua área resolver, mas seu colega pode. (C. DENT II - M, C/D) No trabalho interdisciplinar, cada um tem uma especificidade..., mas isso não quer dizer que está isolado. A interdisciplinaridade é justamente você perpassar esses caminhos, é você poder dar a sua contribuição e também adquirir outros conhecimentos. (A. SOCIAL I - M A/B)

Observamos, nessas falas, uma forma ainda incipiente de busca/desejo dos profissionais de promover a abertura para o diálogo e a troca de experiências com os outros profissionais/ saberes. Apesar de nossa pesquisa não objetivar a análise das práticas, pudemos observar limites no exercício do diálogo e na troca de experiências nas atividades de grupo por nós acompanhadas por nós no trabalho de campo. Em sua grande maioria, tais atividades contavam apenas com a presença de um ou dois profissionais, sendo justificada a ausência dos demais membros da equipe por estes estarem ocupados com outros afazeres.

A importância do exercício da comunicação é enfatizada por Souza (1999). Segundo a autora, a comunicação, ainda que de forma parcial, deve existir, de modo que cada visão disciplinar possa contribuir para o compartilhamento com outras disciplinas.

Durante as entrevistas, uma fala se destacou ao representar o trabalho interdisciplinar como:

Vários profissionais trabalhando em conjunto, cada um com sua contribuição, cada um com seu perfil, mas que no fim se completa. Por exemplo, a dentista tem um problema que não pode resolver enquanto a sua competência de dentista; ela precisa do serviço social, ela conversa com a assistente social, aí tenta resolver o problema. Da mesma forma, o 
médico, o auxiliar, o agente comunitário de saúde, etc, precisa do restante da equipe. Então o trabalho vai se completando. ...é necessário que exista outros profissionais que possam fazer aquilo que aquele outro não pode, porque cada profissional tem o seu limite de competência..., porque, se não fosse assim, não interessaria ter a questão da interdisciplinaridade. Cada profissional saberia tudo, então não poderia ter essa gama aí de profissionais atuando de forma conjunta; trabalho interdisciplinar eu entendo assim. (ACS I - H, A)

Nesse caso, o entrevistado compreende os limites e os saberes das diversas profissões, pressupondo a superação da concepção unilateral do trabalho em equipe, que envolve troca de saberes e divisão de poder, sem, contudo, negar as especificidades das profissões, o que faz com que a relação de poder se horizontalize. Outro ponto a ser destacado na fala do agente comunitário de saúde é a idéia de complementaridade, na medida em que os profissionais buscam a contribuição dos outros membros da equipe como forma de ampliar seus horizontes. Como afirma Demo (1997, p. 103), a interdisciplinaridade requer a presença de um grupo de cientistas. Nesse sentido, o trabalho em equipe é a base para um trabalho interdisciplinar à medida que os conhecimentos buscam convergir para constituir um "texto único, escrito a muitas mãos".

Remetendo-nosà TRS, Moscovici (2004) afirma existir nas sociedades contemporâneas duas classes distintas de universos de pensamento, que se entrelaçam dialeticamente: os Universos Consensuais (UC) e os Universos Reificados (UR). Nesses, circulam as ciências, a objetividade, o rigor lógico e metodológico. Aos Universos Consensuais, correspondem as atividades do senso comum e as práticas interativas do dia a dia. Verificamos em nossa pesquisa que a representação do trabalho interdisciplinar como complemento/ contribuição/vários profissionais trabalhando juntos nos leva aos universos reificados do saber.

\section{Trabalho interdisciplinar como construção}

Apenas uma vez o trabalho interdisciplinar é representado, pelos entrevistados, como construção. Vejamos a fala a seguir:

Interdisciplinar é uma construção de uma rede, certo? ...é você reconhecer e ver os atributos dos outros colegas, é como a gente trabalha a interdisciplinaridade dentro de um trabalho em equipe, é quando você busca outros profissionais da área, é o agente comunitário de saúde, o auxiliar de enfermagem, o enfermeiro, o assistente social e o médico, a pirâmide inverteu, certo? O saber de todos é valorizado, e não apenas o do médico. (ENF II - M, C)

Essa representação traz elementos que se aproximam do conceito de trabalho interdisciplinar, apontando, sob certos aspectos, a relação horizontalizada entre os profissionais. Além disso, é interessante observar que, ao fazer referência à "inversão da pirâmide", a entrevistada nos remete à idéia da perda da hegemonia do poder médico e revela o entendimento da necessidade de "diluição" do poder no trabalho em saúde. Esse pensamento também pôde ser constatado na fala de outro profissional:

Eu acho que ela é valorizada (enfermeira), a gente tem direito a vez e voto... Acho que, como a enfermeira, a gente avançou bastante com o PSF...; eu já trabalhei em hospital particular, e a gente não era tão valorizada...; agora melhorou bastante; com o PSF, a gente vê crescimento na enfermagem. (ENF $I-M, B)$

Destacamos que, nos últimos anos, a enfermagem vem buscando construir saber 
e prática diferentes daqueles que são tradicionalmente exercidos nas instituições hospitalares. Com a implantação do PSF, a enfermagem se traduz na busca de maior compromisso social, e, segundo a entrevistada acima, tem sido mais valorizada.

\section{Trabalho interdisciplinar entendido como integralidade}

Alguns entrevistados, quando indagados sobre "o que você entende por trabalho interdisciplinar?", representam o mesmo como "integralidade", como na seqüência discursiva abaixo:

...o usuário, ele é atendido numa forma integral por todas as pessoas da equipe. (A. SOCIAL I - M, A/B)

Por outro lado, é possível constatar, na fala desse profissional, em outro momento da sua entrevista, uma prática muito comum no trabalho em saúde, qual seja, a justaposição de disciplinas sem a necessária integração conceitual.

A gente tem um trabalho aqui que a gente faz com as gestantes, então a gestante, ela passa pela enfermeira. Da enfermagem e do auxiliar, todo aquele atendimento do pré-natal, aí ela passa também pelo médico, que faz toda aquela parte clínica e de orientação...; mas ela passa por quem também? Ela passa pela assistente social pelas questões que diz respeito às questões sociais e aí, complementando, tem toda aquela atenção também na área da odontologia. Então, assim, uma usuária, ela passa por todos os setores e assim, quanto mais outros tivesse, ela também passaria... $O$ usuário, ele é atendido numa forma integral por todas as pessoas da equipe. (A. SOCIAL $\mathrm{I}-\mathrm{M}, \mathrm{A} / \mathrm{B})$

Nesse caso, o trabalho interdisciplinar é representado como simples encaminhamento e/ou repasse de problemas de um profissional para outro. De acordo com Peduzzi (1998), o trabalho coletivo, nessa perspectiva, não é realizado pelo profissional da saúde, mas sim, pelo usuário, que peregrina de sala em sala, ou até mesmo de serviço em serviço.

Encontramos RS semelhantes nos estudos realizados por Schneider, Durman e Dias (2001, citado por Costa, 2002). Os autores alertam para a inexistência de interdisciplinaridade nessa forma de trabalho em que o usuário é responsabilizado pela integração, ainda que deficitária, do trabalho em saúde, na medida em que é obrigado a procurar várias especialidades.

Desconhecimento do que seja trabalho interdisciplinar

Durante nossa pesquisa, vários entrevistados, ao serem in dagados sobre o que vem a ser o trabalho interdisciplinar, mostraramse confusos, revelando a dificuldade de apropriação desse conceito:

Não sei, eu já ouvi, mas não lembro (risos). (ACS I - M, B)

Como assim? Estou por fora, não entendi bem, uma disciplina? (ACS II - M, D)

...aquele trabalho disciplinado (risos) é aquele trabalho que você tem hora, tem momento certo, com disciplina. (AE I-M, B)

Verifica-se que o auxiliar de enfermagem se refere ao trabalho interdisciplinar, se considerarmos nossos referenciais teóricos, de maneira equivocada, na medida em que o concebe como um trabalho que tem hora, que tem momento certo.

Movidos pelo desconhecimento do conceito de interdisciplinaridade, alguns entrevistados expressam representações tautológicas, como explicitamos a seguir:

Um trabalho interdisciplinar é um trabalho interdisciplinas. (ACS II - M, C) 
É como um trabalho com várias disciplinas. (ACD I-M, A/B)

Chamamos a atenção para o fato de que o desconhecimento do que seja interdisciplinaridade é evidenciado, principalmente, por parte dos profissionais de nível médio (os agentes comunitários de saúde e o auxiliar de consultório dentário). Por outro lado, é fundamental destacarmos que tal desconhecimento é compreensível, tendo em vista que até mesmo no meio acadêmico ainda não se chegou a uma definição precisa do termo.

\section{Considerações finais}

Na nossa pesquisa, se tomarmos como referência as contribuições teóricas sobre o trabalho em equipe que norteiam as atuais políticas de saúde, as RS dos profissionais do PSF revelaram limites, mais do que avanços.

Embora os profissionais entrevistados tenham ressaltado a importância do caráter interdisciplinar, suas representações indicam que os mesmos desenvolvem basicamente trabalhos isolados ou em pares. Eles valorizam a participação de diferentes profissões/ profissionais no interior da equipe, mas suas representações não são reveladoras da interação entre esses saberes. Também constatamos que em nenhum momento foram feitas referências ao saber da comunidade, sendo mais destacado e valorizado o conhecimento formal/acadêmico. Esses aspectos também foram constatados em nossas observações de campo.

A referência ao trabalho em equipe apresentouse quase que restrita ao componente multiprofissional, que pressupõe a ausência nos cursos/capacitações de discussões que abordem os componentes diferenciais do trabalho. Foi possível perceber, assim, que a proposta de um trabalho interdisciplinar está presente mais na filosofia do PSF que no fazer cotidiano das equipes.

Os profissionais que atuam no PSF foram formados/capacitados dentro de uma concepção baseada no paradigma flexneriano, no qual se privilegia a abordagem individual, curativa e centrada nos hospitais. Tal fato constitui um desafio para os referidos profissionais, uma vez que se encontram organizados em equipe. Em geral, os profissionais egressos dessa formação apresentam dificuldades em transcender o espaço do consultório médico e em propor diagnósticos e intervenções em nível coletivo, em uma abordagem integralizadora/ humanizadora.

Consideramos que o grande desafio que se apresenta para as equipes é romper com esse paradigma tradicionalmente calcado no corporativismo, na estrutura verticalizada de poder e na fragmentação do conhecimento.

Entendemos que a discussão dos conceitos de interdisciplinaridade dentro da realidade do PSF é de fundamental importância para provocar mudanças no perfil dos diversos profissionais envolvidos com a estratégia de saúde da família, pois o trabalho em equipe implica um trabalho coletivo, no qual cada profissional coloque seus conhecimentos, sentimentos e expectativas em função de um objetivo partilhado.

Apesar das dificuldades apresentadas, acreditamos que o trabalho compartilhado no PSF pode ser formador, concorrendo para novas práticas em saúde devido ao processo de relações interpessoais nas quais os 
profissionais podem compartilhar e construir um conhecimento contínuo sobre o seu fazer de forma mais solidária e democrática. Inegavelmente, a partir da implantação do PSF em Campina Grande, modificações relevantes marcaram a nova gestão do trabalho em saúde, em particular, na forma de trabalhar dos profissionais. O trabalho em equipe no PSF iniciou um processo de resgate da valorização profissional por meio de melhor remuneração e da possibilidade de refletir sobre a condução do processo de trabalho, com o objetivo de integrar os profissionais que, até então, pouco se relacionavam em seus cotidianos de trabalho. 


\section{Rosana Farias Batista Leite *}

Psicóloga, mestre em Saúde Coletiva pela Universidade Estadual da Paraíba - UEPB

Professora da Faculdade de Ciências Médicas de Campina Grande - FCM

Departamento de Enfermagem e Fisioterapia

\section{Thelma Maria Grisi Veloso}

Psicóloga, doutora em Sociologia pela Universidade Estadual Paulista - UNESP

Professora do Departamento de Psicologia da Universidade Estadual da Paraíba - UEPB

Vinculada ao Mestrado em Saúde Coletiva - UEPB

E-mail: thelma.veloso@ig.com.br

* Endereço para correspondência:

Rua José Augusto Ribeiro, 115, Res. Portinari, ap. 501 Bairro: Bela Vista Cep: 58109-045 Campina Grande-PB

E-mail: rosanafleite@uol.com.br

Recebido 02/03/2007 Reformulado 26/03/2008 Aprovado 27/03/2008

\section{Referências}

Bardin, L. (1977). Análise de conteúdo. Lisboa: Edições 70.

Costa, R. P. (2002). Interdisciplinaridade e equipes de saúde: um estudo de caso. Dissertação de Mestrado em Engenharia de Produção, Universidade Federal de Santa Catarina, Florianópolis.

Demo, P. (1997). Conhecimento moderno sobre ética: intervenção do conhecimento. Rio de Janeiro: Vozes.

Farias, A. F. M. R. (2005). Vivências de sofrimento e prazer no trabalho: a dor e a delícia de ser trabalhador do Saúde da Família em Campina Grande. Dissertação de Mestrado em Saúde Coletiva, Universidade Estadual da Paraíba, Campina Grande, PB.

Japiassu, H. (1976). Interdisciplinaridade e patologia do saber. Rio de Janeiro: Imago.

Mendes, E. V. (1996). Uma agenda para a saúde. São Paulo: Hucitec.

Ministério da Saúde. (2003). Pólos de educação permanente em saúde: diretrizes para a sua organização. Brasília, DF: Autor.

Ministério da Saúde. (2001). Departamento de Atenção Básica. Guia prático do programa saúde da família. Brasília, DF: Autor.

Moscovici, S. (2004). Representações sociais: investigações em psicologia social (2a ed., P. A. Guareschi, trad.). Petrópolis, RJ: Vozes.

Parreiras, P. C., \& Martins Júnior, T. (2004). A proposta políticopedagógica da Escola de Formação em Saúde da Família Visconde de Sabóia. Sanare. Revista de Políticas Públicas, Sobral, ano V(1.), 21-32.
Peduzzi, M. E. (2001). Equipe multiprofissional de saúde: conceito e tipologia. Revista de Saúde Pública, 35(1). Recuperado em 17 de maio de 2005, da SciELO (Scientific Electronic Library Online): http://www.scielo.com.br

Peduzzi, M. E. (1998). Equipe multiprofissional de saúde: A interface entre trabalho e interação. Tese de Doutorado em Saúde Coletiva, Faculdade de Ciências Médicas, Universidade Estadual de Campinas, Campinas, SP.

Péret, T.C.O. (2001). Programa Saúde da Família: questões e perspectivas - A experiência desenvolvida no Município de Campina Grande-PB (1994-1999). Dissertação de Mestrado em Serviço Social, Departamento de Serviço Social, Pontifícia Universidade Católica do Rio de Janeiro, Rio de Janeiro.

Sá, C. P. (1996). Núcleo central das representações sociais. Rio de Janeiro: UERJ; Petrópolis, RJ: Vozes.

Sá, C. P. (1998). A construção do objeto de pesquisa em representações sociais. Rio de Janeiro: UERJ; Petrópolis, RJ: vozes.

Souza, A. S. (1999). A interdisciplinaridade e o trabalho coletivo em saúde. Revista de Atenção Primária à Saúde, 2(2), 10-14.

Souza, A. S., \& Mourão, A. M. A. (2002). A construção do trabalho em equipe: uma tarefa do coletivo dos profissionais em saúde. Revista de Atenção Primária à Saúde, 4(10).

Teixeira, M. J. O., \& Nunes, S. T. (2004). A interdisciplinaridade no Programa Saúde da Família: uma utopia? In M. I. S. Bravo et al., Saúde e serviço social. Rio de Janeiro: Cortez. 